\title{
Complexity of Denture Plaque Biofilms
}

\author{
Pierre Le Bars $^{1, *}$, Alain Kouadio ${ }^{2}$ and Fabienne Jordana ${ }^{3}$ \\ ${ }^{1}$ Faculty of Dentistry, University of Nantes, France - University Hospital of Nantes, France \\ ${ }^{2}$ Faculty of Dentistry, University Felix Houphouet Boigny d'Abidjan, Côte D'Ivoire \\ ${ }^{3}$ Faculty of Dentistry, University of Nantes - INSERM Institute UMR S 791, France
}

${ }^{\star}$ Corresponding author: Pierre Le Bars, Faculty of Dentistry, University of Nantes, France - University Hospital of Nantes, France; E-mail: Pierre.Le-Bars@univ-nantes.fr

Received: November 11, 2020; Accepted: November 18, 2020; Published: November 20, 2020

\begin{abstract}
Background: This article provides an overview of denture plaque as both a microbiota community and a biofilm. The most promising strategies to ascertain the differences between biofilms formed by commensal populations and those related to increased pathogenesis and persistent infections are discussed.

This literature review covers the microbial communities colonizing dentures and their relationship to oral health. Supported by in vivo and in vitro studies, we highlight emerging-targeting strategies for physical and mechanical therapies intended to limit biofilm formation. Nevertheless, many challenges to eradicating mature biofilms are discussed.

Conclusions: Oral biofilms in the denture wearer can be controlled with daily hygiene but cannot be totally eradicated. To prevent the pathogenesis of denture biofilm, the biomass on the denture surface and the bioburden in the oral cavity must be reduced focusing on not only the inhibition of putative pathogens, but also interference with environmental factors that drive selection and enrichment.
\end{abstract}

Clinical implications: An effective oral hygiene regimen targeting dentures, saliva planktonic cells, mucosa, and the remaining teeth, whether or not they are affected by periodontal diseases, is necessary to control biofilm, particularly in the presence of many general diseases.

Keywords: Bacteria, Candida, Dental plaque biofilm, Microbiome, Denture management

\section{Introduction}

Insertion in the oral cavity of a removable denture bathed in saliva is an ideal environment for dynamic biofilm development $[1,2]$. In these conditions the planktonic microbiota exposed to stress and flow can quickly create favorable conditions for denture biofilm growth. This is defined as a community of bacteria attached to the denture surface and surrounded by an extracellular matrix produced by the bacteria themselves. This matrix is composed of different elements such as exopolysaccharides, proteins or DNA. Under the denture, the combination of soft tissue and hard surfaces provides a favorable environment within the oral cavity for microbial colonization. During use, the denture is subjected to many factors such as composition and flow of saliva, food, temperature fluctuations, masticatory forces and appliance loading. These parameters are challenging from the clinical point of view. Under healthy conditions, these denture plaques are tolerated by patients. But in $7-60 \%$ of patients denture plaque is associated with stomatitis [3]. Denture stomatitis (DS) is considered as a polymicrobial biofilm-mediated oral disease. Clinically DS refers to erythema and edema of the soft palate and tissues of the oral cavity that are in close contact with the denture surface.

Mature natural and denture teeth biofilms have similar total numbers of bacteria but different proportions of species [4]. Furthermore, the bacterial communities residing on the teeth and dentures of a single person are similar to each other independently of the surface material, and therefore denture health could impact the maintenance of the remaining teeth and vice-versa [5].

Although denture plaque cannot be totally eradicated, it can be controlled solely by oral hygiene measures that include a daily regimen of brushing the mucosa and denture, completed by rinsing with an antimicrobial mouthrinse [6]. This effective oral hygiene regimen can help control denture plaque biofilm and is a practical approach to the prevention of denture stomatitis and in addition accrues benefits in certain systemic diseases [7].

\section{Biofilm Formation in Oral Environments}

The oral microbiota includes a wide range of microorganisms, representing the three domains of life: Archea, Virus, Bacteria and Eukarya, providing numerous opportunities for physical and chemical interactions between different species and kingdoms [810]. Oral environments present a constant and transient micro flora whose quantitative and qualitative composition depends on many factors such as individual factors related to general conditions such as still birth, nutrition composition and consistency, and general diseases. However, locally other parameters are involved such as oral hygiene, tooth extraction, sampling times during the day, oral health status, prosthesis restorations, dental and periodontal diseases and dental treatment $[11,12]$. On the other hand, the apparent 
discrepancies between recent findings and previous 16S rRNA gene-based sequencing studies can stem from other parameters, ranging from geographical differences between patient populations to sample collection, sequencing (choice of 16S rRNA target region, the sequencing platform used, available read length and sequencing depth), or DNA extraction and PCR protocols [13].

Within the oral cavity, microorganisms are often found as part of highly organized microbial communities termed biofilms. Multispecies in biofilms, form complex microbial communities while maintaining their own autonomy and covering the different surfaces according to different micro environments such as teeth, saliva $\left(10^{8}\right.$ microbes per milliliter), tongue, gingiva and other epithelial surfaces of the oral mucosae [14]. Some denture surfaces can carry up to $10^{11}$ organisms per gram in wet weight of plaque. Within this ecosystem, each species will produce metabolic intermediates, signaling molecules and toxins that will accumulate and impact the physiology of other members of the community [15].

During the early stages of biofilm formation, it is known that planktonic bacteria attach directly to the surfaces of the oral cavity or indirectly bind to other bacterial cells that have already colonized $[16,17]$. Other planktonic cells such as Candida spp possess a wide arsenal of glycoproteins located at the exterior side of the cell wall, many of which play a decisive role in these steps. In vivo, Candida spp. are members of mixed biofilms and subject to various antagonistic and synergistic interactions [18].

Consequently, Candida biofilm, even in the limited oral niche such as on dentures, decreases bacterial diversity and then changes the composition of the oral microbiota [19].

\section{Composition of Denture-associated Biofilm}

Available data conservatively estimate that at least ten fold more bacteria than yeasts colonize the surface of dentures. The prosthetic base acts as a support for the oral microbiota at the epithelial surface and is externally in contact with the planktonic flora. With time some organisms can penetrate inside the resin [20,21]. The palatal and mandibular covering mucosa, alternatively in contact with the removable prosthesis during the day and then released during the night, presents a particular ecosystem. In these conditions, the complexity of denture-associated biofilm increases, with the contact between the biotic layer of epithelial cells and the abiotic denture base (metallic or plastic biomaterials). These two dynamic biofilms coexist momentarily for many hours every day and are separate during the night, following the recommendations regarding the wearing of removable prostheses. Risk factors underlying stomatitis of the dental prosthesis must also be identified and treated: some prostheses need to be redone (inadequate prosthesis, unstable), certain diseases can interfere with wearing the removable prosthesis (general pathologies, diabetes, immunocompromised patients, cholesterol, lung and digestive diseases, cancers) and taking medication that can disrupt salivary secretion [7].

Recent and former investigations of the microbiome have examined the microbial communities colonizing dentures and their relationship to oral health $[4,5,22]$. Denture-associated biofilms have been considered a reservoir for infectious disease agents [23]. In these conditions, the relations between oral microbial infections and numerous systemic disease conditions are should be reconsidered [24].

In many studies, Candida was not limited to denture stomatitis samples $[25,26]$. Candida occur as two different phenotypes, i.e., the planktonic form (free cells) or the sessile form (biofilms). The sessile phenotype involves the development of a group of strains on a polymeric matrix, which confers protection against the host immune response and prevents diffusion of antimicrobial drugs. Therefore, infections caused by Candida biofilms remain difficult to diagnose and treat [27]. The genus Candida as hyphae or pseudohyphae is associated with the proliferation and development of biofilms [28]. The virulence of $C$. albicans has been closely linked to the hyphaeforming ability [29-32].

In denture wearers, the interactions that lead to an increased pathogenicity of fungi and bacteria are particularly intriguing [33,34]. The study of mixed C. albicans-bacterial biofilms, although only beginning, has already revealed unanticipated synergies that further complicate the treatment of biofilms in the clinic.

\section{Denture Biofilm Management}

Oral bacteria were long considered as individual cells, not being capable of complex behaviors. Today this simplistic vision of bacterial life has evolved and we know that bacteria are able to communicate with each other (Quorum Sensing) and live in association. Denture biofilm management has become increasingly important since awareness has arisen of their involvement in many public health issues. In fact, dentures give bacteria increased resistance to physical forces, antibiotic treatments and even the host immune system. This multifactorial resistance is due in particular to the presence of the extracellular matrix of biofilms, which contain structural proteins and enzymes that allow the formation and maintenance of these "microbe cities". However, today the mechanisms that govern the secretion of substrates composing this matrix are unknown.

In these conditions, prevention via maintenance of a normal health-associated ecosystem is key for denture wearers. Recently new inquiries have influenced the upkeep of the denture.

Firstly, the numbers of bacteria colonizing the dentures of healthy subjects was significantly less than the numbers colonizing the dentures of stomatitis. These concern the proportions and frequency of isolation of Mutans streptococci; lactobacilli, bifidobacteria and yeasts were significantly greater in subjects with denture stomatitis [35].

Second, a recent study using the $16 \mathrm{~S}$ rRNA gene sequencing data suggested a new approach considering the apparent strong mutual influence of bacteria colonizing dentures and teeth in the same individual (species/phylotypes). The health and integrity of the remaining teeth could be important factor in the mucosal health of denture wearers beyond their role in anchoring restorations and maintaining bone integrity. Similarly, the denture-associated oral mucosal health status could play a critical role in conserving the remaining teeth [5]. 
Third, an interesting finding was the detection of periodontal pathogens, Aggregatibacter actinomycetemcomitans and Porphyromonas gingivalis, on the tongue of edentulous subjects, as these species were thought to disappear after removal of all natural teeth $[36,37]$. Under these conditions the cleaning of the tongue becomes necessary to eliminate these pathogens.

Fourth, while overlap exists, different natural surfaces within the oral cavity are colonized by distinct communities. The recent technology to identify the oral microbiome can detects new information. In vivo, earlier studies have demonstrated that protein adsorption to surfaces and bacterial adherence are mostly determined by the surface roughness rather than by other material with specific physicochemical properties)_[38,39]. Shi et al's findings give additional information and assume that individual-specific factors can be more dominant determinants of the oral bacterial biofilm community composition than surface [5]. Many parameters support these arguments: an important host factor involving saliva can display substantial variability between individuals [40] and provides important adhesion proteins for bacterial attachment [38]. It assumes that individual-patient factors could be stronger determinants of bacterial biofilm community composition than different surfaces and emphasizes that grouping and pooling of samples from different people can influence the outcome of analysis.

Fifth, previous studies analyzing the bacteria colonizing dentures in health and disease (denture stomatitis) are not conclusive. Similar to these results, a recent sequencing study [26] and older culturebased approaches [20] found no difference in the apparent microbial composition between healthy and stomatitis patients and noted only that the amount of plaque buildup is significantly greater in stomatitis patients. Hence the need to fight daily against the accumulation of microbial plaque.

Sixth, there is widespread use of recently developed new therapies to prevent, disrupt and otherwise render harmless the peculiar ability of $C$. albicans to form biofilms on almost any surface in the mouth. Commercially available probiotics (Accuflora ${ }^{\mathrm{R}}$ and Culturelle ${ }^{\mathrm{R}}$ ) that contain Lactobacillus species associated with mechanistic cleaning interfere with the in vitro ability of $C$. albicans to form biofilm on dentures [41]. Through the phenomena of co-aggregation, the lactobacilli may secrete an adequate mass and be able to maintain a hostile micro-environment around Candida species with high concentrations of products such as acids, $\mathrm{H}_{2} \mathrm{O}_{2}$, bacteriocins, and thereby possibly inhibit the pathogens' growth. Daily use of probiotic lozenges may reduce the prevalence of high oral Candida counts in frail elderly nursing homes residents [42]. Recently a probiotic, the bacterium Lactobacillus reuteri (DSM 17938 and ATCC PTA 5289) against six oral Candida species (C. albicans, C. glabrata, C. krusei, C. tropicalis, C. dubliniensis and C. parapsilosis) were tested in vitro for their ability to co-aggregate and inhibit the growth of the yeasts. The lactobacilli almost completely inhibited the growth of C. Albicans and C. parapsilosis, but did not affect C. krusei, the latter can resist from the acids produced by the lactobacilli [33].

Another domain of research is examining nanoparticles. The effect of zirconia nanoparticles added to cold-cured acrylic resin on $C$. albicans adhesion has been evaluated. Zirconium oxide nanoparticles possess antifungal properties on C. albicans and Aspergillus niger and could be used for prevention of DS $[43,44]$. Another interesting finding in vivo is the efficacy of methylene blue-mediated photodynamic inactivation on the oral mucosa and prostheses of patients with DS, against C. albicans [45].

For all this progress, the treatment is based the ecological plaque hypothesis, which states that disease prevention should not only focus on the inhibition of putative pathogens, but also on interference with the environmental factors that drive selection and enrichment these microbiota, as reported by Marsh [46].

The key characteristics of denture biofilm that could be targets for pathogen management include its behavior as an adhesive mass with viscoelastic properties. The placement of the biofilm obeys different sequences that can condition the maintenance of the prosthesis.

In the first stage, the pathogen management process consists of regular meticulous brushing of the prosthesis every day to reduce the pathogenic burden [47].

The second phase of antimicrobial therapy, including the use of mouthwashes, is intended to impede the passage of stage I (adhesion) biofilm to stage II biofilm by applying them at key intervals to combat attachment and maturation of the biofilm [48].

Many chemotherapeutic products and interventions recommended are effective against planktonic oral bacteria, but unfortunately live intact biofilms are able to persist even after treatment with many products such as sodium hypochlorite [49]. In vitro studies show that MoWs containing chlorhexidine digluconate or cetylperyridinium chloride may be favorable for oral health in terms of microbial balance [50]. However, these data must be confirmed by comparative in-depth in vivo studies.

In the presence of prosthetic stomatitis and after detection in culture of colonization by Candida, the use of Amphotericin B is considered the "gold standard" of antifungal therapy but is toxic because there is no selectivity between fungal and mammalian cells [51]. However, fungal biofilms that mature on denture material become resistant to antifungals [52].

In conclusion, four recommendations concerning the use of a removable prosthesis, written and verbal, are addressed to patients. 1) Daily brushing of the prosthesis. 2) Daily immersion of the prosthesis in an antiseptic liquid. 3) Refrain from wearing your prosthesis at night. 4) When you get up in the morning, rinse your mouth and its prosthesis well before reintroducing it in the mouth.

\section{Reference}

1. Nikawa H, Hamada T, Yamamoto T (1998) Denture plaque - past and recent concerns. J Dent 26: 299-304. [crossref]

2. Hao Y, Huang X, Zhou X, Li M, Ren B, et al. (2018) Influence of Dental Prosthesis and Restorative Materials Interface on Oral Biofilms. Int J Mol Sci 19: 3157. [crossref]

3. Gendreau L, Loewy ZG (2011) Epidemiology and Etiology of Denture Stomatitis. J Prosthodont 20: 251-260. [crossref]

4. Teles FR, Teles RP, Sachdeo A, Uzel NG, Song XQ, Torresyap G, et al. (2012) Comparison of Microbial Changes in Early Redeveloping Biofilms on Natural Teeth and Dentures. J Periodontol 83: 1139-1148. [crossref] 
5. Shi B, Wu T, McLean J, Edlund A, Young Y, et al. (2016) The Denture-Associated Oral Microbiome in Health and Stomatitis. Imperiale MJ, éditeur. mSphere 1: 00215-216. [crossref]

6. Ercalik-Yalcinkaya S, Ozcan M (2014) Association between Oral Mucosal Lesions and Hygiene Habits in a Population of Removable Prosthesis Wearers. J Prosthodont Off J Am Coll Prosthodont 17.

7. Senpuku H, Sogame A, Inoshita E, Tsuha Y, Miyazaki H, et al. (2003) Systemic diseases in association with microbial species in oral biofilm from elderly requiring care. Gerontology 49: 301-309. [crossref]

8. Marloes Lof, Marleen Janus, Bastiaan Krom (2017) Metabolic Interactions between Bacteria and Fungi in Commensal Oral Biofilms. J Fungi 3: 40.

9. Avila M, Ojcius DM, Yilmaz Ö (2009) The Oral Microbiota: Living with a Permanent Guest. DNA Cell Biol 28: 405-411. [crossref]

10. Chevalier M, Ranque S, Prêcheur I (2018) Oral fungal-bacterial biofilm models in vitro: a review. Med Mycol 56: 653-667. [crossref]

11. Marsh PD, Do T, Beighton D, Devine DA (2016) Influence of saliva on the oral microbiota. Periodontol 2000 70: 80-92. [crossref]

12. Marsh PD (2005) Dental plaque: biological significance of a biofilm and community life-style. J Clin Periodontol 32: 7-15. [crossref]

13. Zheng W, Tsompana M, Ruscitto A, Sharma A, Genco R, et al. (2015) An accurate and efficient experimental approach for characterization of the complex oral microbiota. Microbiome 3: 48. [crossref]

14. Zarco MF, Vess TJ, Ginsburg GS (2012) The oral microbiome in health and disease and the potential impact on personalized dental medicine. Oral Dis 18: 109-120. [crossref]

15. Jakubovics NS (2015) Intermicrobial Interactions as a Driver for Community Composition and Stratification of Oral Biofilms. J Mol Biol 427: 3662-3675. [crossref]

16. Hojo K, Nagaoka S, Ohshima T, Maeda N (2009) Bacterial Interactions in Dental Biofilm Development. J Dent Res 88: 982-990. [crossref]

17. ten Cate JM, Klis FM, Pereira-Cenci T, Crielaard W, de Groot PWJ (2009) Molecular and cellular mechanisms that lead to Candida biofilm formation. J Dent Res 88: 105115. [crossref]

18. ten Cate JM, Klis FM, Pereira-Cenci T, Crielaard W, de Groot PWJ (2009) Molecular and cellular mechanisms that lead to Candida biofilm formation. J Dent Res 88: 105115. [crossref]

19. Lyon JP, da Costa SC, Totti VMG, Munhoz MFV, de Resende MA (2006) Predisposing conditions for Candida spp. carriage in the oral cavity of denture wearers and individuals with natural teeth. Can J Microbiol 52: 462-467. [crossref]

20. Theilade E, Budtz-Jørgensen E, Theilade J (1983) Predominant cultivable microflora of plaque on removable dentures in patients with healthy oral mucosa. Arch Oral Biol 28: 675-680. [crossref]

21. Latib YO, Owen CP, Patel M (2018) Viability of Candida albicans in Denture Base Resin After Disinfection: A Preliminary Study. Int J Prosthodont 31: 436-439. [crossref]

22. Campos MS, Marchini L, Bernardes La.S, Paulino LC, Nobrega FG (2008) Biofilm microbial communities of denture stomatitis. Oral Microbiol Immunol 23: 419-424. [crossref]

23. Gendron R, Grenier D, Maheu-Robert L (2000) The oral cavity as a reservoir of bacterial pathogens for focal infections. Microbes Infect 2: 897-906. [crossref]

24. Le Bars P, Sébastien Matamoros, Fabienne Jordana, Emmanuel Montassier, Françoise Le Vacon, et al. (2017) The oral cavity microbiota: between health, oral disease and cancers of the aerodigestive tract. Can J Microbiol 63: 475-492. [crossref]

25. Koopmans ASF, Kippuw N, de Graaff J (1988) Bacterial Involvement in Dentureinduced Stomatitis. J Dent Res 67: 1246-1250. [crossref]

26. O'Donnell LE, Robertson D, Nile CJ, Cross LJ, Riggio M, et al. (2015) The Oral Microbiome of Denture Wearers Is Influenced by Levels of Natural Dentition. PLOS ONE 10: 0137717. [crossref]

27. Gusberti FA, Gada TG, Lang NP, Geering AH (1985) Cultivable microflora of plaque from full denture bases and adjacent palatal mucosa. J Biol Buccale 13: 227-236. [crossref]
28. Altarawneh S, Bencharit S, Mendoza L, Curran A, Barrow D, et al. (2013) Clinical and Histological Findings of Denture Stomatitis as Related to Intraoral Colonization Patterns of Candida albicans, Salivary Flow, and Dry Mouth: Role of C. albicans in Saliva, Mucosal and Denture Surfaces in DS. J Prosthodont 22: 13-22. [crossref]

29. Mitchell KF, Zarnowski R, Sanchez H, Edward JA, Reinicke EL, Nett JE, et al. (2015) Community participation in biofilm matrix assembly and function. Proc Natl Acad Sci 112: 4092-4097. [crossref]

30. Mayer FL, Wilson D, Hube B (2013) Candida albicans pathogenicity mechanisms. Virulence 4: 119-128. [crossref]

31. Tsang PW-K, Bandara HMHN, Fong W-P (2012) Purpurin Suppresses Candida albicans Biofilm Formation and Hyphal Development. PLoS ONE 7: 50866.

32. Vylkova S, Lorenz MC (2014) Modulation of Phagosomal pH by Candida albicans Promotes Hyphal Morphogenesis and Requires Stp2p, a Regulator of Amino Acid Transport. Krysan DJ, éditeur. PLoS Pathog 10: 1003995. [crossref]

33. Jørgensen MR, Kragelund C, Jensen PØ, Keller MK, Twetman S (2017) Probiotic Lactobacillus reuteri has antifungal effects on oral Candida species in vitro. J Oral Microbiol 9: 1274582. [crossref]

34. Bor B, Cen L, Agnello M, Shi W, He X (2016) Morphological and physiological changes induced by contact-dependent interaction between Candida albicans and Fusobacterium nucleatum. Sci Rep 6: 27956. [crossref]

35. Mantzourani M, Gilbert SC, Fenlon M, Beighton D (2010) Non-oral bifidobacteria and the aciduric microbiota of the denture plaque biofilm. Mol Oral Microbio 25:190-199. [crossref]

36. Sachdeo A, Haffajee AD, Socransky SS (2008) Biofilms in the edentulous oral cavity. J Prosthodont Off J Am Coll Prosthodont 17: 348-356. [crossref]

37. Fernandes CB, Aquino DR, Franco GC, Cortelli SC, Costa FO, et al. (2010) Do elderly edentulous patients with a history of periodontitis harbor periodontal pathogens? Clin Oral Implants Res 21: 618-623. [crossref]

38. Teughels W, Van Assche N, Sliepen I, Quirynen M (2006) Effect of material characteristics and/or surface topography on biofilm development. Clin Oral Implants Res 17: 68-81. [crossref]

39. Ionescu AC, Brambilla E, Azzola F, Ottobelli M, Pellegrini G, et al. (2019) Laser microtextured titanium implant surfaces reduce in vitro and in situ oral biofilm formation. PLoS ONE 13: 0202262. [crossref]

40. Altarawneh S, Bencharit S, Mendoza L, Curran A, Barrow D, et al. (2013) Clinica and histological findings of denture stomatitis as related to intraoral colonization patterns of Candida albicans, salivary flow, and dry mouth. J Prosthodont Off J Am Coll Prosthodont 22: 13 22. [crossref]

41. Ujaoney S, Chandra J, Faddoul F, Chane M, Wang J, et al. (2014) In Vitro Effect of Over-the-Counter Probiotics on the Ability of Candida Albicans to Form Biofilm on Denture Strips. J Dent Hyg JDH Am Dent Hyg Assoc 88: 183-189. [crossref]

42. Kraft-Bodi E, Jørgensen MR, Keller MK, Kragelund C, Twetman S (2015) Effect of Probiotic Bacteria on Oral Candida in Frail Elderly. J Dent Res 94: 181-186. [crossref]

43. Gad M, Al-Thobity AM, Shahin S, Alsaqer B, Ali A (2017) Inhibitory effect of zirconium oxide nanoparticles on Candida albicans adhesion to repaired polymethyl methacrylate denture bases and interim removable prostheses: a new approach for denture stomatitis prevention. Int J Nanomedicine 12: 5409-5419. [crossref]

44. Dos Santos Ramos MA, Da Silva P, Spósito L, De Toledo L, Bonifácio B, et al. (2018) Nanotechnology-based drug delivery systems for control of microbial biofilms: a review. Int J Nanomedicine. févr;Volume 13: 1179-1213. [crossref]

45. de Senna AM, Vieira MMF, Machado-de-Sena RM, Bertolin AO, Núñez SC, et al (2018) Photodynamic inactivation of Candida ssp. on denture stomatitis. A clinical trial involving palatal mucosa and prosthesis disinfection. Photodiagnosis Photodyn Ther 22: 212-216. [crossref]

46. Marsh PD, Zaura E (2017) Dental biofilm: ecological interactions in health and disease. J Clin Periodontol 44: 12-22. [crossref]

47. Ramage G, O’Donnell L, Sherry L, Culshaw S, Bagg J, Czesnikiewicz-Guzik M, et al (2019) Impact of frequency of denture cleaning on microbial and clinical parameters - a bench to chairside approach. J Oral Microbiol Janv 11: 1538437. [crossref]

48. Koo H, Allan RN, Howlin RP, Stoodley P, Hall-Stoodley L (2017) Targeting microbia biofilms: current and prospective therapeutic strategies. Nat Rev Microbiol 15: 740755. [crossref] 
Pierre Le Bars (2020) Complexity of Denture Plaque Biofilms

49. A, Sarembe S, Pizzey RL, Axe AS, Bradshaw DJ (2016) Material compatibility and antimicrobial activity of consumer products commonly used to clean dentures. $J$ Prosthet Dent 115: 189-198. [crossref]

50. Ardizzoni A, Pericolini E, Paulone S, Orsi CF, Castagnoli A, et al. (2018) In vitro effects of commercial mouthwashes on several virulence traits of Candida albicans, viridans streptococci and Enterococcus faecalis colonizingthe oral cavity. PLOS ONE 13: 0207262 [crossref]
51. Pierce CG, Lopez-Ribot JL (2013) Candidiasis drug discovery and development: new approaches targeting virulence for discovering and identifying new drugs. Expert Opin Drug Discov 8: 1117-1126. [crossref]

52. Hawser SP, Douglas LJ (1995) Resistance of Candida albicans biofilms to antifungal agents in vitro. Antimicrob Agents Chemother 39: 2128-2131. [crossref] 